The color of pure ceric oxide is not due to the presence of nitrogen from the air, since the color is the same if ignited in pure oxygen.

The author wishes to thank Mr. H. S. Miner and Mr. M. C. Whitaker, of the Welsbach Company, for samples of material and advice, and especially to thank Professor Ames and Dr. Frank L. Cooper for the time spent and interest taken in establishing the purity of the products, and the impurity of the starting material.

The purity of the finished product is further established by the work of Metzger in this issue; the sample is named by him " 4. ."

general Chemistry laboratory,

HAVEMBYER HALL, COLVMBIA UNIVERSITY.

[CONTRIBUtToNS FroM THE HAVEMEYer LABORATORIES, COLUMBIA UNIVERSITY, No. I63.]

\title{
A RAPID AND ACCURATE VOLUMETRIC METHOD FOR THE DETERMINATION OF CERIUM IN THE PRESENCE OF OTHER RARE EARTHS.
}

BY F. J. METZGER.

Received February 27, 1909.

The basis for the method described in this communication may be briefly stated as follows: cerous sulphate, in sulphuric acid solution, is converted quantitatively to ceric sulphate by means of sodium bismuthate. The excess of sodium bismuthate is then removed by filtration, a known excess of ferrous sulphate added to reduce the ceric compound, the excess of ferrous sulphate being then titrated with potassium permanganate.

The oxidation and subsequent reduction of the cerium may be represented thus:

$$
\mathrm{Ce}^{+++} \longrightarrow \mathrm{Ce}^{++++} \longrightarrow \mathrm{Ce}^{+++}
$$

from which it is apparent that to secure accurate results, the ferrous sulphate and permanganate solutions should be dilute.

Solutions Required.-A potassium permanganate solution approximately $N / 40$.

A solution containing Io grams of Mohr's salt and $50 \mathrm{cc}$. of concentrated sulphuric acid per liter. The value of the permanganate in terms of iron multiplied by 3.08415 gives its value in terms of $\mathrm{CeO}_{2}$ (1909 at. wts.).

Experimental.-Solutions of five different cerium salts were prepared and carefully standardized for combined rare earth oxides by precipitating as oxalate, igniting and weighing. ${ }^{1}$

2 The author is indebted to Messrs. M. C. Whitaker and H. S. Miner, of the Welsbach Light Co., for samples Nos. I, 2, and 3 indicated in the table below, and to A. C. Neish, for samples Nos. 4 and 5 . 
The method is carried out as follows: To $50 \mathrm{cc}$. of the cerium nitrate solution add $20 \mathrm{cc}$. of concentrated sulphuric acid and evaporate to fumes of sulphur trioxide. ${ }^{1}$ Cool, add 2 grams of ammonium sulphate crystals and carefully dilute with $80 \mathrm{cc}$. of water. Add I gram of sodium bismuthate and heat to boiling. Cool somewhat and add $50 \mathrm{cc}$. of 2 per cent. sulphuric acid. Filter through a Gooch crucible and wash with I00-I50 cc. of 2 per cent. sulphuric acid. Add standard ferrous sulphate solution in excess (as shown by the change from yellow to colorless) and titrate back with permanganate.

The accuracy of the determination is shown by the results obtained on the five solutions.

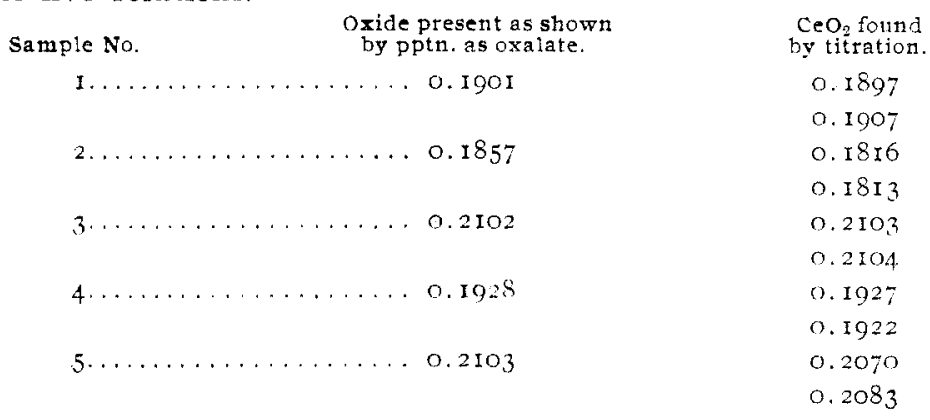

It is apparent that samples Nos. 2 and 5 contain other rare earths as impurity, whereas samples Nos. I, 3 and 5 are pure products.

The method is very rapid, requiring only $15^{-20}$ minutes to complete a determination after the earths have been obtained in solution in the sulphate form.

To test the effect, if any, which other rare earths would have on the method, four solutions were prepared, each of which contained salts equivalent to the following, expressed in grams: $\mathrm{ThO}_{2}, 0.10 ; \mathrm{La}_{2} \mathrm{O}_{3}$, 0.10; $\mathrm{Nd}_{2} \mathrm{O}_{3}, 0.05 ; \mathrm{Pr}_{4} \mathrm{O}_{7}, 0.05 ; \mathrm{Y}_{2} \mathrm{O}_{3}, 0.05 ; \mathrm{Er}_{2} \mathrm{O}_{3}, 0.075 ; \mathrm{ZrO}_{2}, 0.05 ; \mathrm{Sm}_{2} \mathrm{O}_{3}$, $0.025 ; \mathrm{Gd}_{2} \mathrm{O}_{3}, 0.05 ; \mathrm{TiO}_{2}, 0.02$.

It was assumed that some of these might contain a small amount of cerium as impurity and consequently two of the solutions were analyzed as a blank, while to each of the other two was added $50 \mathrm{cc}$. $(=0$. Igo I $\mathrm{CeO}_{2}$ ) of solution "No. I" above. The results obtained by titration were:

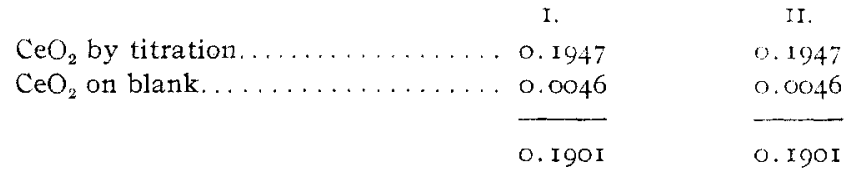

1 This evaporation to fumes of sulphur trioxide is unnecessary if the earths are in solution as sulphates. In the latter case it is simply necessary to have sulphuric acid and water present in the proportion I acid : 4 water. 
None of the earths above mentioned interferes with the determination of the cerium.

Remarks on the Method.-In the earlier experiments made, larger quantities of sodium bismuthate were employed ( $3-5 \mathrm{~g}$.) and no ammonium sulphate was added. This amount, however, gave a heavy precipitate of basic bismuth salt when the solution was heated to boiling, which invariably carried with it a small amount of ceric sulphate which could not be removed by subsequent washing. The ammonium sulphate prevents the precipitation of the basic bismuth salt, so that there is left only a small amount of undecomposed sodium bismuthate to be filtered off. The same Gooch crucible may be used for a large number of filtrations. The following determinations on solution "No. 3" above will illustrate the importance of the ammonium sulphate in the method.

$\begin{array}{ccc}\mathrm{CeO}_{2} \text { taken. } & \text { Without }\left(\mathrm{NH}_{4}\right)_{2} \mathrm{SO}_{4} . & \text { With }\left(\mathrm{NH}_{4}\right)_{2} \mathrm{SO}_{4} . \\ 0.2 \mathrm{IO} 2 & 0.2067 & 0.2103 \\ \ldots \ldots & 0.2062 & 0.2104\end{array}$

Delicacy of the Reaction.-Experiments show that the yellow color produced by oxidation of the cerium by means of the bismuthate affords a very sensitive test for minute quantities of cerium. A solution containing $0.2 \mathrm{mg}$. of $\mathrm{CeO}_{2}$ in $100 \mathrm{cc}$. gives a distinct yellow coloration. The intensity of the color increases with increasing temperature. Experiments are now being made with the hopes of devising a colorimetric method for the determination of small quantities of cerium in the presence of other rare earths, such a mixture, for example, as obtains in incandescent mantles.

The titration method is being applied to the analysis of cerium minerals, monazite sand, and incandescent mantles. ${ }^{1}$ The method of W. \& M., however, involves oxidation in a strong nitric acid solution by means of bismuth tetroxide, the cerium being then reduced in nitric acid solution by a known excess of hydrogen peroxide and the excess of the latter titrated with permanganate. Three titrations were made on a cerium solution containing unknown amounts of lanthanum and didymium.

QUANTitative Laboratory.

[CONTRIBUTION FROM THE UNIVERSITY OF WASHINGTON.]

\section{ANALYSIS OF MIXTURES OF HALOGEN ACIDS.}

By William M. Dehn.

Received February 27, 1909.

In an alkaline sodium "hypobromite solution," prepared by adding bromine to an excess of caustic soda, the bromine is present in three

1 The above method had been worked out before a method by Waegner and Müller (Ber., 36, 282 (1903)), had been noticed. 